\title{
Climate effects on an inland alpine lake in Xinjiang, China over the past 40 years
}

\author{
HuiXia CHAI ${ }^{1}$, WeiMing $\mathrm{CHENG}^{1 *}$, ChengHu ZHOU ${ }^{1}$, ShangMin $\mathrm{ZHAO}^{2}$, HaiJiang $\mathrm{LIU}^{3}$ \\ ${ }^{1}$ State Key Laboratory of Resources and Environmental Information System, Institute of Geographic Sciences and Natural Re- \\ sources Research, Chinese Academy of Sciences, Beijing 100101, China; \\ ${ }^{2}$ Department of Surveying Mapping, College of Mining Technology, Taiyuan University of Technology, Taiyuan 030024, China; \\ ${ }^{3}$ China National Environmental Monitoring Center, Beijing 100012, China
}

\begin{abstract}
Inland lakes are important water resources in arid and semiarid regions. Understanding climate effects on these lakes is critical to accurately evaluate the dynamic changes of water resources. This study focused on the changes in Sayram Lake of Xinjiang, China, and addressed the effects of climate fluctuations on the inland lake based on long-term sequenced remote sensing images and meteorological data from the past 40 years. A geographic information system (GIS) method was used to obtain the hypsometry of the basin area of Sayram Lake, and estimation methods for evaporation from rising temperature and water levels from increasing precipitation were proposed. Results showed that: (1) Areal values of Sayram Lake have increased over the past 40 years. (2) Both temperature and precipitation have increased with average increases of more than $1.8^{\circ} \mathrm{C}$ and $82 \mathrm{~mm}$, respectively. Variation of the water levels in the lake was consistent with local climate changes, and the areal values show linear relationships with local temperature and precipitation data. (3) According to the hypsometry data of the basin area, the estimated lake water levels increased by $2.8 \mathrm{~m}$, and the water volume increased by $12.9 \times 10^{8} \mathrm{~m}^{3}$ over the past 40 years. The increasing area of Sayram Lake correlated with local and regional climatic changes because it is hardly affected by human activities.
\end{abstract}

Keywords: Sayram Lake; climate change; water body extraction; areal variation; inland alpine lake

Citation: HuiXia CHAI, WeiMing CHENG, ChengHu ZHOU, ShangMin ZHAO, HaiJiang LIU. 2013. Climate effects on an inland alpine lake in Xinjiang, China over the past 40 years. Journal of Arid Land, 5(2): 188-198.

Inland alpine lakes are a sensitive indicator of climate change (Guo et al., 2003). Changes occurring in these lakes can reflect regional climate variations. Such lakes are an important water resource in arid and semiarid regions (Fan and Li, 1984; Qin, 1999) and the impacts of climate change on the water levels in these lakes have delayed effects. Fluctuations in water level significantly affect local climate. Consequently, it is necessary to study water level changes and examine the evolution of these lakes and the effects on local natural environments.

The clear understanding of inland lake variation under climate change is critical to accurately evaluate water resources and to retrieve climate information from lakes. An increasing number of studies (Fan and Li, 1984; Hu et al., 2002; Angel and Kunkel, 2010; Bai et al., 2011) indicated that many inland lakes in arid and semiarid regions have decreased in surface area since 1950. Bates et al. (2008) indicated that no globally consistent trend of lake water levels has been found. Most lake levels in the basin regions of Qinghai (China), Australia, Africa (e.g. Zimbabwe, Zambia, and Malawi), North America (e.g. North Dakota), and Europe (e.g. central Italy) have decreased because of the combined effects of drought, global warming and human activities (Bates et al., 2008; Bai et al., 2011). Indeed, many lakes (such as Ebinur Lake, Aydingkol Lake, and Lop Nur) in Xinjiang of China are shrink-

*Corresponding author: WeiMing CHENG (E-mail: chengwm@1reis.ac.cn) Received 2012-07-23; revised 2012-09-23; accepted 2012-10-04

(C) Xinjiang Institute of Ecology and Geography, Chinese Academy of Sciences, Science Press and Springer-Verlag Berlin Heidelberg 2013 
ing and even drying up. In contrast, the water levels of a small number of mountain lakes in Inner Mongolia, Xinjiang, and the Qinghai-Tibet Plateau have risen because of increased snow and glacier melt. All these studies indicated that lakes undergo different processes and are affected by the local climate. In the Sayram Lake, which is located in the Tianshan Mountains (Xinjiang, China), the water level has slightly increased over the past 40 years. According to available records, the lake area has been constantly growing (Ma et al., 2003; Gao and Jia, 2005; Ding et al., 2006; Hu, 2007; Bai et al., 2011). However, detailed analysis of the lake variation and the quantitative effects of the local climate have not, to date, been presented.

This study focused on the changes in Sayram Lake using data from remote sensing images, and analyzed trends and the relationship between areal values of the lake and meteorological data (precipitation and temperature) over the past 40 years. From our findings, we can monitor local climate changes, because Sayram Lake is little affected by human activities.

\section{Data and methods}

The Sayram Lake region was selected as the study area. Long-term sequenced Landsat Multi-spectral Scanner (MSS), Thematic Mapper (TM)/Enhanced Thematic Mapper Plus (ETM+) images and meteorological data from four stations around the lake were used. Three methods, supervised classification, single-band threshold, and the Normalized Difference

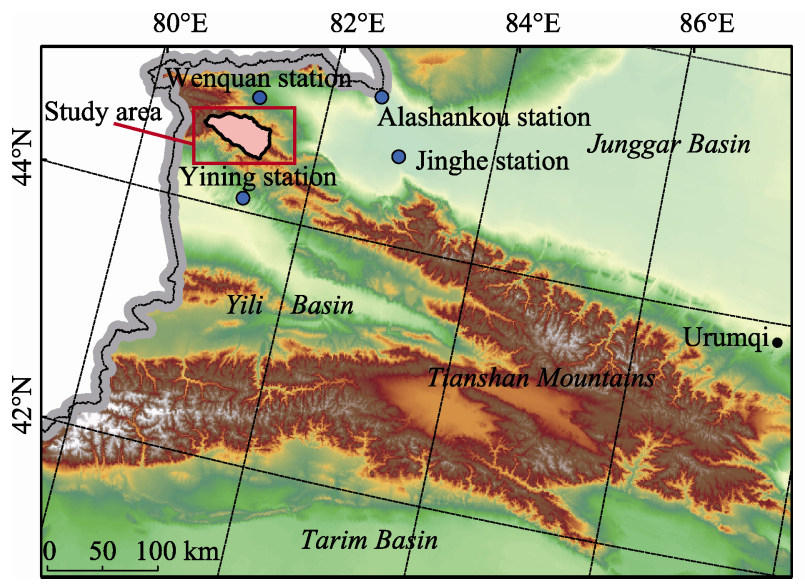

Fig. 1a Location of the study area
Water Index (NDWI) based on a geographic information system (GIS) and remote sensing images, were used to extract water body information.

\subsection{Study area}

Sayram Lake, renowned as a "pearl" along the Silk Road, is the largest alpine lake and the highest cold water inland lake in Xinjiang Uygur autonomous region, China (Figs. 1a, b). It is situated between $44^{\circ} 28^{\prime} 00^{\prime \prime}-44^{\circ} 46^{\prime} 00^{\prime \prime} \mathrm{N}$ and $80^{\circ} 55^{\prime} 00^{\prime \prime}-81^{\circ} 25^{\prime} 00^{\prime \prime} \mathrm{E}$. Sayram is $27 \mathrm{~km}$ in length from east to west, and 30 $\mathrm{km}$ from north to south. It has an elevation of 2,073 m asl.

There are more than 20 small rivers supplied by alpine glacier and snow melt in the Sayram Lake basin, and about 10 small villages where the local people are engaged in animal grazing for a living, and there is no agriculture or industry. Thus, the basin suffers from few human disturbances. There is only one national road passing through on the southeast side of the lake (Ma et al., 2003).

The basin shows stratiform and circular geomorphologic characteristics. From the lake center to mountaintops, geomorphologic units are in the following sequence: the water body of the lake, lacustrine plain, alluvial-lacustrine plain, alluvial fan plain, alluvial plain, alluvial-pluvial fan plain, alluvial-pluvial plain, fluvial hill, mid-altitude fluvial mountain, high-altitude periglacial mountain, and high-altitude glacial mountain (Yang, 2011). Generally, the south and east of the lake are steeper than the terrain in other directions (Fig. 2).

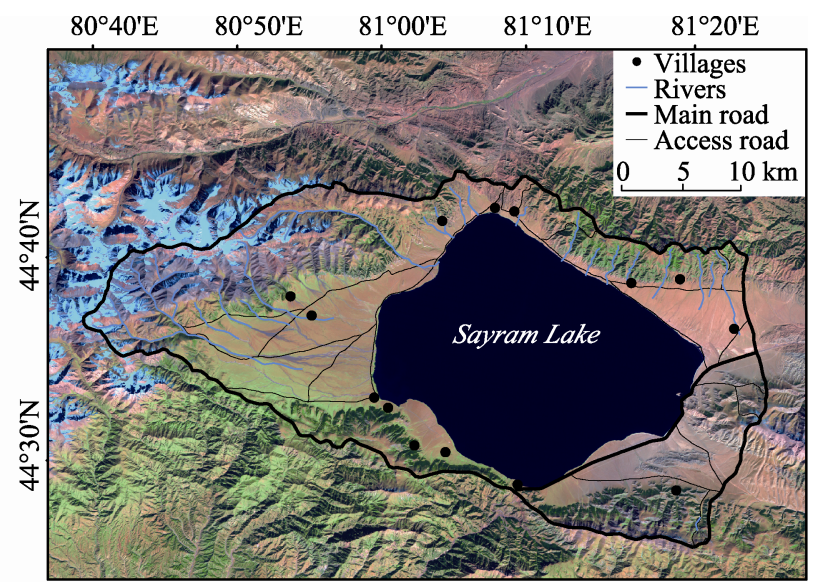

Fig. 1b Topographic map of the study area 


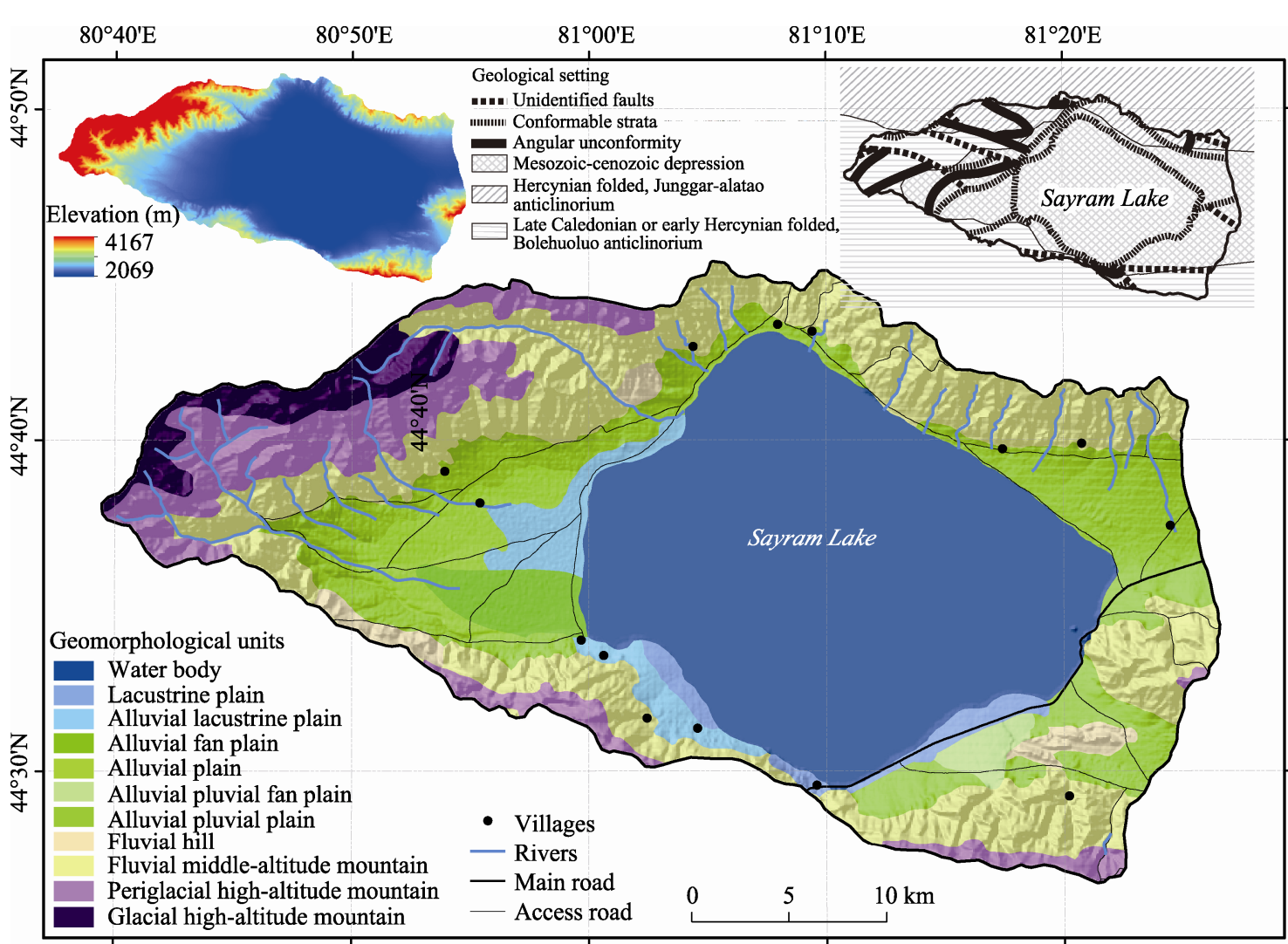

Fig. 2 Geomorphological map of the Sayram Lake area. Taken from Shuttle Radar Topography Mission digital elevation model (SRTM-DEM). Upper left: pseudocolor map of SRTM-DEM; Upper right: geological setting.

Sayram was a fresh water lake before the late Pleistocene when its water could drain (Xinjiang Institute of Geography, the Chinese Academy of Sciences, 1986). However, it is now a salt water lake with closed-lake basin characteristics (Hu et al., 2002).

Geologically, the Sayram Lake basin is a graben fault basin (Xinjiang Institute of Geography, the Chinese Academy of Sciences, 1986), located on the northern limb of the Bolehuoluo anticlinorium. It belongs to the Hercynian fold belt, indicating that Sayram is a fracture lake. The lake was formed in the Pliocene or early Pleistocene (Ma et al., 2003). According to drilling data, Quaternary deposits, geologic and topographic maps (Xinjiang Institute of Geography, the Chinese Academy of Sciences, 1986), the lake covered the largest area in the middle Pleistocene; after which its area gradually decreased.

\subsection{Data}

\subsubsection{Meteorological data}

The water supply of Sayram Lake is from the melt water of glaciers and snow, as well as from rainfall
(Xinjiang Integrated Scientific Investigation Team of the Chinese Academy of Sciences, 1966). As the water of the lake is not easily utilized by humans, the lake is little affected by human activities. The lake water level is relatively stable in summer (June, July and August) and autumn (September, October and November) (Ma et al., 2003).

During the past 40 years, climate change has greatly influenced the lake (Shi and Zhang, 1995). It has affected the regional water cycle in the drainage basin, which is related to rainfall, evaporation, and meltwater of glaciers and snow (Ma et al., 2003).

There are no hydrological or meteorological records for the Sayram Lake area, because of the lack of large rivers in the study area (Ma et al., 2003). In the study, we used the daily observed data from four meteorological stations (Wenquan, Alashankou, Jinghe and Yining) near Sayram Lake during the period 1970-2009 (Fig. 1a). The data comply with national and province benchmarks. After analyzing meteorological data quality, some data were filtered out because they were deemed invalid or produced unreasonable temporal sequences. Daily temperature re- 
cords from Jinghe and Yining are continuous from 1970 to 2009, and daily precipitation records extend from 1970 to 2004. For Wenquan and Alashankou stations, daily precipitation and temperature records are from 1970 to 2004.

\subsubsection{Remote sensing data}

The quality of images from June to October is better than that for other months. According to cloud percent and acquisition data (Earth Resources Observation and Science Center, 2013), we chose images from summer or autumn (June-September) as the representatives of various periods (1972, 1975-1978, 1990, 1998-2011). Information on the source, acquisition date and spatial resolution of all remote sensing images were listed in Table 1.

Table 1 Information on the remote sensing images

\begin{tabular}{cccc}
\hline & Landsat MSS & Landsat TM & Landsat ETM \\
\hline & 22 Sep 1972; 8 Nov 1975; & 27 Aug 1990; 2 Oct 1998; & 26 Aug 1999; 28 Aug 2000; 14 Jul \\
Acquisition date & 16 Oct 1976; 25 Jun 1977; & 21 Aug 2006; 24 Aug 2007; & 2001; 18 Aug 2002; 20 Jul 2003; 24 \\
& 13 Aug 1978 & 30 Sep 2009; 3 Oct 2010; 19 Aug 2011 & Sep 2004; 27 Sep 2005; 15 Jun 2008 \\
\hline Resolution (m) & 90 & 30 & 30 \\
\hline
\end{tabular}

We also obtained data from the Shuttle Radar Topography Mission Digital Elevation Model (SRTM-DEM) (CGIAR-CSI, 2008; Earth Resources Observation and Science Center, 2013), with a horizontal resolution of $90 \mathrm{~m}$ (Fig. 2). In addition, we used early research results and data records (Hu et al., 2002; Gao et al., 2005; Bai et al., 2011) as reference.

\subsection{Methods}

1.3.1 Geometric rectification of remote sensing images

Because of the low resolution of all remote sensing images and extraction of only water body information, the remote sensing image from 2011 was geometrically rectified on 1:100,000 topographic maps. More than 20 GCPs (error within two pixels) equally distributed across the whole area were selected to obtain a geometrically rectified image which was regarded as a reference benchmark. Other images from different years were also geometrically rectified and the errors were controlled within two pixels.

\subsubsection{Extraction of water body}

There are currently many water information extraction methods by remote sensing images (McFeeters, 1996; Du and Zhou, 1998; Zhou et al., 2000, 2003; Liu and Jezek, 2004; Gao and Jia, 2005; Ouma and Tateishi, 2006; Zhu et al., 2007; Yang et al., 2011). These methods were implemented in unified models, which achieved full separation of water and background through integrated computation of the entire image (Luo et al., 2009).

McFeeters (1996) indicated that the NDWI method can restrain ground vegetation information to the greatest extent, and highlight water information. It also can effectively separate water information from shadows. We therefore adopted the water index NDWI to extract water information based on GIS and remote sensing images. We also used topographic images to realize the information extraction of water body. The topographic information was derived from the SRTM-DEM. It has been shown that this extraction method is effective (Luo et al., 2009; Bai et al., 2011; Li et al., 2011).

To compare the result and remove defects of the single method, we used supervised classification and single-band threshold methods. Thus, the final areal values of different years are arithmetic averages from the results of the three methods.

1.3.3 Analysis of precipitation and temperature data

We calculated the monthly average precipitation, mean annual precipitation, monthly average temperature and annual mean temperature from 1960-2009, using data from around Sayram Lake to analyze the main factors for lake changes. Correlation analysis was used to explain trends and the relationship between areal values of the lake and meteorological data.

\subsubsection{Hypsometry of the lake basin area}

Based on topographic and geomorphological characteristics of the watershed, especially slope changes in the flat plain around the lake, we obtained the hypsometry of the basin area according to the Spatial Analyst tool of ArcGIS. The flowchart and operational process is shown in Fig. 3. 


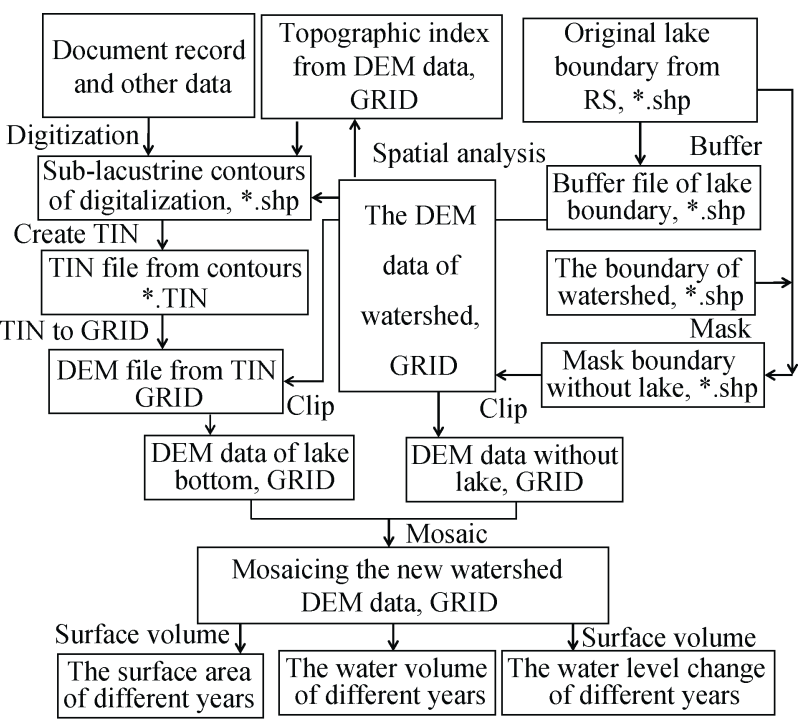

Fig. 3 Flowchart of hypsometry and surface volume of the lake basin area

First, we constructed the DEM data of the watershed from the SRTM-DEM. The original lake boundary (in 1972) was obtained from the remote sensing image, and the data were buffered for some distance to infill interspace. Based on historical data and slope changes from DEM data of the flat plain, sub-lacustrine contours were digitalized and assigned values. A triangulated irregular network (TIN) was built according to the sub-lacustrine contours, and the TIN data were transformed into raster format (GRID). DEM data of the lake bottom were clipped by the buffered boundary, giving lake-bottom raster data (GRID).

Second, we overlaid watershed and lakeshore boundaries to obtain the mask boundary without the lake; the watershed DEM data were clipped by the latter boundary. The lake-bottom and without-lake DEMs were mosaicked, thereby constructing the new watershed DEM data, with sub-lacustrine topography.

Third, the surface volume from ArcGIS was used to calculate the water level, surface area, and water volume in different years, allowing their changes and relationships to be analyzed.

1.3.5 Estimating lake expansion from increasing precipitation and water evaporation from rising temperature

From vertical spectrum distribution characteristics of the Tianshan Mountains, the elevation gradient $(E G)$ was estimated. Based on the surface volume tool in
ArcGIS, the surface area $(S A ; 3 \mathrm{D})$ of the entire watershed above the lake water level was computed. Average increase in the amount of precipitation $(A P)$ at the benchmark meteorological station was calculated. The lake expansion from increasing precipitation $(I P)$ was calculated using Eq. 1:

$$
I P=S A \times E G \times A P / 1000 .
$$

As with the water levels from precipitation, the elevation gradient of evaporation amount was estimated. Taking average evaporation intensity of one station as the benchmark, we calculated water evaporation intensity $(E I)$ in the study area. According to the surface volume tool in ArcGIS, only the lake water area $(L A ; 2 \mathrm{D})$ is obtained. Evaporation gradient $(E G)$ intensity was estimated for a temperature increase of $1{ }^{\circ} \mathrm{C}$. The average rising temperature $(A T)$ of one benchmark meteorological station was computed. Water evaporation from the rising temperature $(R E)$ was calculated using Eq. 2:

$$
R E=L A \times E I \times A T \times E G / 1000 .
$$

\section{Results}

\subsection{Areal variation of Sayram Lake}

The areal variation in the Sayram Lake over the past 40 years is shown in Fig. 4. The lake water area has increased by $12 \mathrm{~km}^{2}$. The areal change is linear, with a correlation coefficient $R^{2}$ of 0.94 . During the 1970s, the water level increased slightly and the lake area was $454 \mathrm{~km}^{2}$.

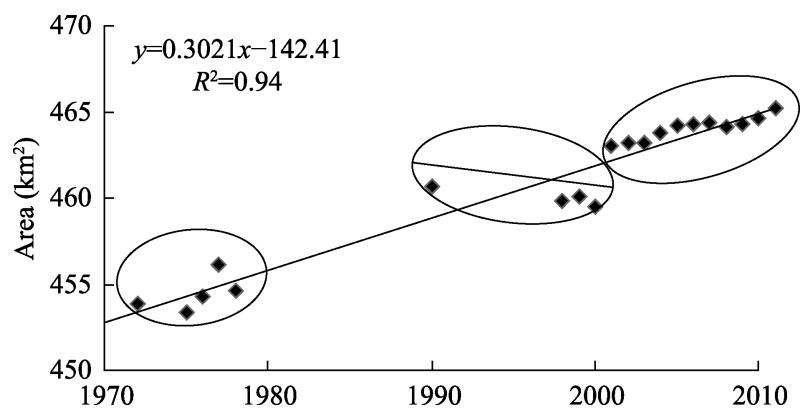

Fig. 4 Areal variation of Sayram Lake, based on remote sensing images over the past 40 years

From 1990 to 2000, the lake area decreased (Fig. 4). However, the extrapolated trend from the 1970s shows that the lake area increased from 454 to $460 \mathrm{~km}^{2}$. Since 2001, the lake area has grown by $5 \mathrm{~km}^{2}$. 


\subsection{Variation of water level, surface area and wa- ter volume of the lake}

According to Fan and Li (1984) and Ma et al. (2003), the surface elevation of Sayram Lake was 2,071.9 m asl, its surface area was $453 \mathrm{~km}^{2}$, its greatest water depth was $106 \mathrm{~m}$, and its average depth was $46.4 \mathrm{~m}$. The lake water volume was $210 \times 10^{8} \mathrm{~m}^{3}$.
To test the accuracy of our hypsometry method, the calculated values and recorded measurements were compared for surface elevation, surface area and water volume (Table 2). The calculated and recorded measurements are in good agreement; therefore, our method can be used to analyze the change of water level, surface area and water volume.

Table 2 Comparison of values from calculation and record documents

\begin{tabular}{lcccc}
\hline \multicolumn{1}{c}{ Items } & Calculating from the method & Documental record & Difference & Difference $(\%)$ \\
\hline Surface elevation $(\mathrm{m})$ & $2,071.6$ & $2,071.9$ & 0.3 & 0.014 \\
Surface area $\left(\mathrm{km}^{2}\right)$ & 453.4 & 453.0 & 0.4 & 0.088 \\
Water volume $\left(\times 10^{8} \mathrm{~m}^{3}\right)$ & 202.6 & 201.0 & 1.6 & 0.592 \\
\hline
\end{tabular}

Using our method, the surface area of $465.3 \mathrm{~km}^{2}$ in 2011 correlates with a water level of $2,074.4 \mathrm{~m}$ asl, and a water volume of $215.5 \times 10^{8} \mathrm{~m}^{3}$. Therefore, the surface area change of the lake is $12 \mathrm{~km}^{2}$ from 1972 to 2011, and the water level increase is $2.8 \mathrm{~m}$, and water volume increase is $12.9 \times 10^{8} \mathrm{~m}^{3}$.

Figure 5 shows the effects of the continuous rise of water level of the lake. Topography in the southeast part of the lake is steep and the old national road and access road were flooded by the rising water, and had to be rebuilt at higher elevations. In addition, the lake islands, formerly connected by bridges which allowed people to access them by foot, are now separated by water, and only boat access is possible.

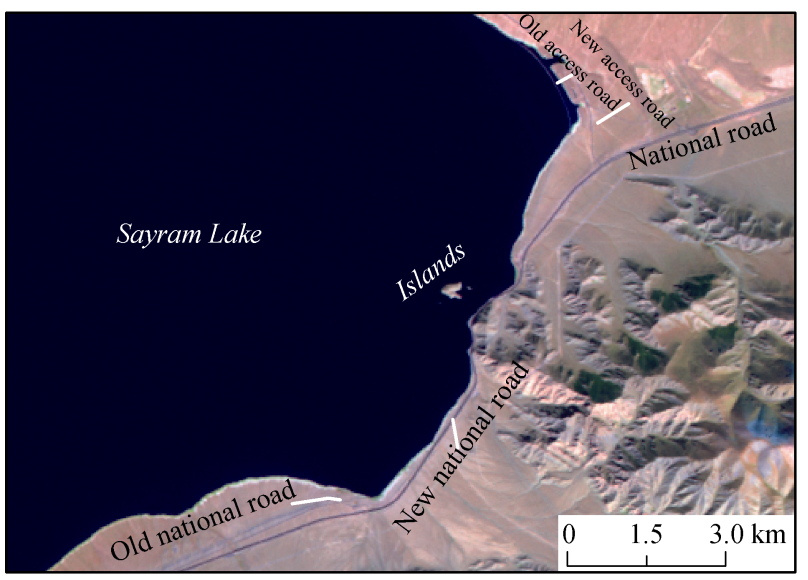

Fig. 5 Map showing flooded roads because of continuous rising lake water levels

\subsection{Climate change analysis of Sayram Lake area}

Lakes in arid regions are very sensitive to changes in water sources (Fan and Li, 1984). Precipitation is an important source, and it is therefore important to study the variation in regional precipitation to determine the changes in Sayram Lake. The Tianshan Mountains intercept and lift water vapor. Consequently, precipitation is greater in these mountains than on the plains, producing an obvious vertical distribution character (Xinjiang Institute of Geography, the Chinese Academy of Sciences, 1986).

Temperature is another important factor for water supplies, as it controls the evaporation of lake water and ice and snow meltwater. Historical records for the past 40 years show that the temperature has increased in the northern Tianshan Mountains, especially in winter (Qin, 1993). Qin (1993) indicated that precipitation has a positive effect and temperature a negative effect on inland lake levels and volumes, but the temperature effect becomes positive when there are numerous glaciers in a watershed.

\subsubsection{Temperature change}

Annual average temperatures were obtained from the four meteorological stations in the study area, and are shown in Fig. 6. The lowest temperature was at

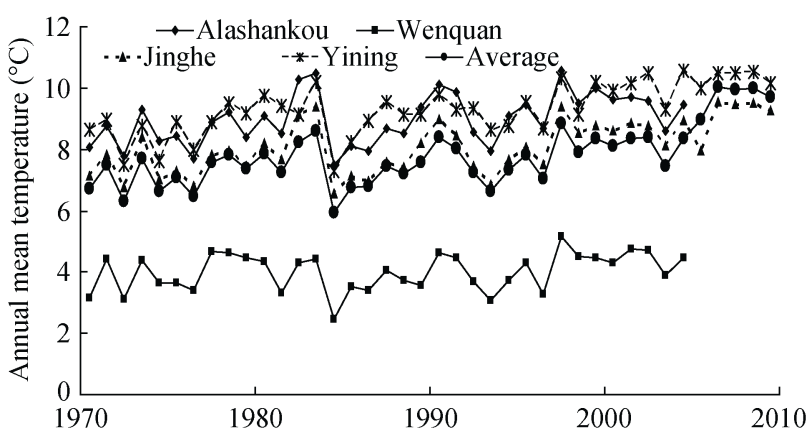

Fig. 6 Annual mean temperature at the meteorological stations around Sayram Lake 
Wenquan (1,500 $\mathrm{m}$ asl) where the annual average was $4^{\circ} \mathrm{C}$. The other three stations, located at lower altitudes, had higher annual average temperatures $\left(8^{\circ} \mathrm{C}\right)$.

From 1970 to 2009 , the annual mean temperature increased and there were three large changes. In 1984, there was a large drop in temperature and in 1990 and 1997, there were substantial temperature increases. Since the 1970s, the annual mean temperature has risen, especially during the $21^{\text {st }}$ century.

Figure 7 shows the annual and decade-mean temperatures at the four stations. The rate of increase in the last decade was greater than those of the previous three.

\subsubsection{Precipitation change}

Figure 8 shows the mean annual precipitation around Sayram Lake. The mean annual precipitation at Wenquan and Yining stations, nearest the lake, increased. The average annual precipitation has increased by $20.3 \%$ since the late 1980s (Bai et al., 2011). Overall, the mean annual precipitation at the four stations has risen slowly.

Since the 1970s, interannual variations of annual precipitation have increased. We can divide the change into two stages, that is, a smaller swing stage

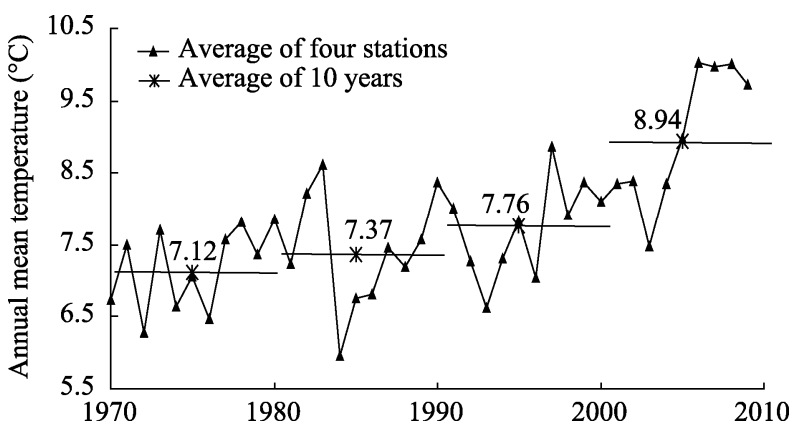

Fig. 7 Annual mean temperature at the four meteorological stations around Sayram Lake

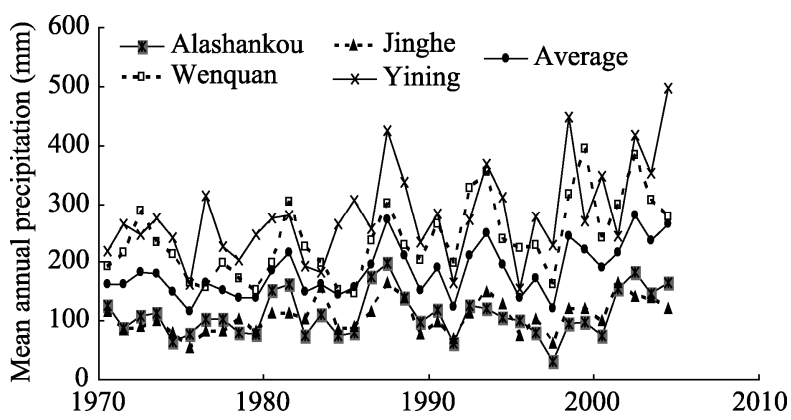

Fig. 8 Mean annual precipitation at the four meteorological stations around Sayram Lake from 1970 to 1985 , and a larger swing stage from 1985 to 2009. Figure 8 shows that the increase in precipitation in Jinghe and Alashankou stations was relatively gentle. This contrasts with the Yining and Wenquan stations, where precipitation significantly increased, especially Yining, where values increased from $219.1 \mathrm{~mm}$ in 1970 to $496.3 \mathrm{~mm}$ in 2004 .

Figure 9 shows annual and decade-average precipitation at the four stations. Yearly and 10-year average temperatures both show gradual increases. The rate of increase from the 1970s to mid-1980s was the smallest.

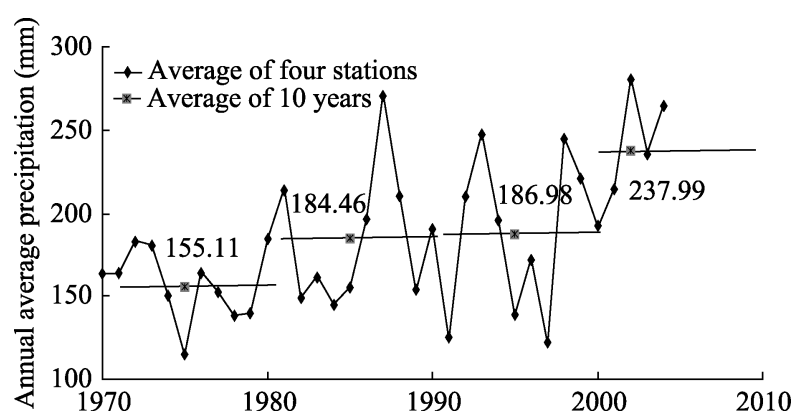

Fig. 9 Annual average precipitation at the four meteorological stations around Sayram Lake

\subsection{Correlation between areal variation and cli- mate change}

To address the correlation between areal variation and temperature and precipitation, we compared the average annual precipitation and annual average temperature from the four stations, and found a positive linear correlation between them (Fig. 10). For areal change and annual average temperature, a linear correlation coefficient $R^{2}$ of 0.68 is obtained; for areal change and average annual precipitation, $R^{2}$ is 0.75 . This indicates that precipitation and temperature increase are principal natural factors in the water increase of the lake. This result is similar to earlier research (Ding et al., 2006), which showed that water level increase is significantly correlated with regional precipitation and surface runoff.

\section{Discussion}

\subsection{Comparison of areal values for Sayram Lake from different sources}

Manual records of areal change of Sayram Lake were 

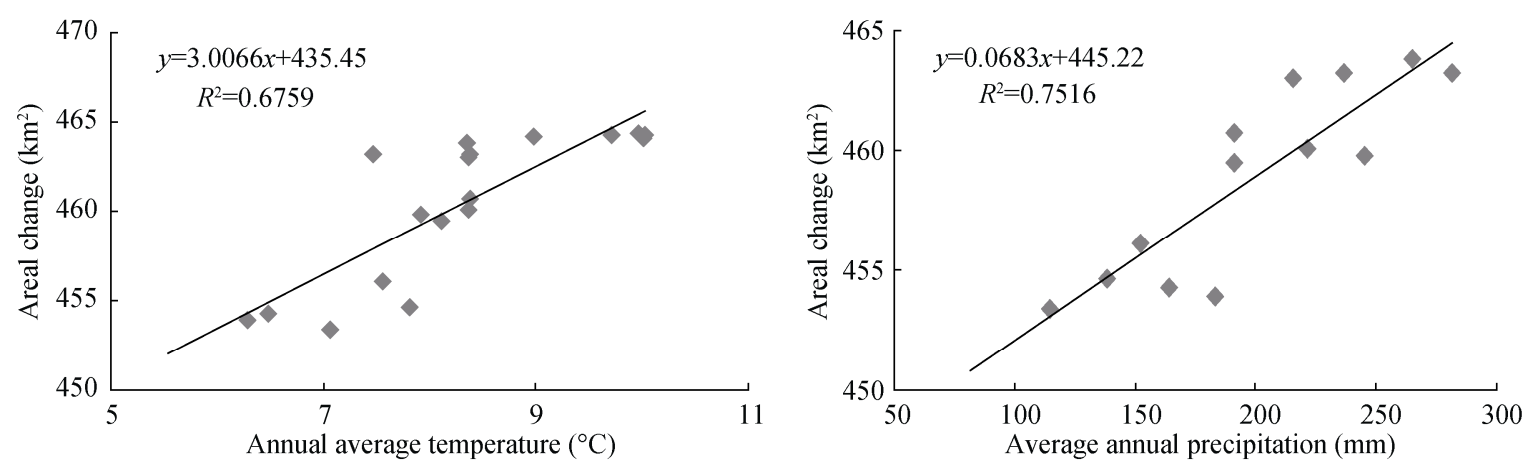

Fig. 10 Correlation between areal change, annual average precipitation and temperature

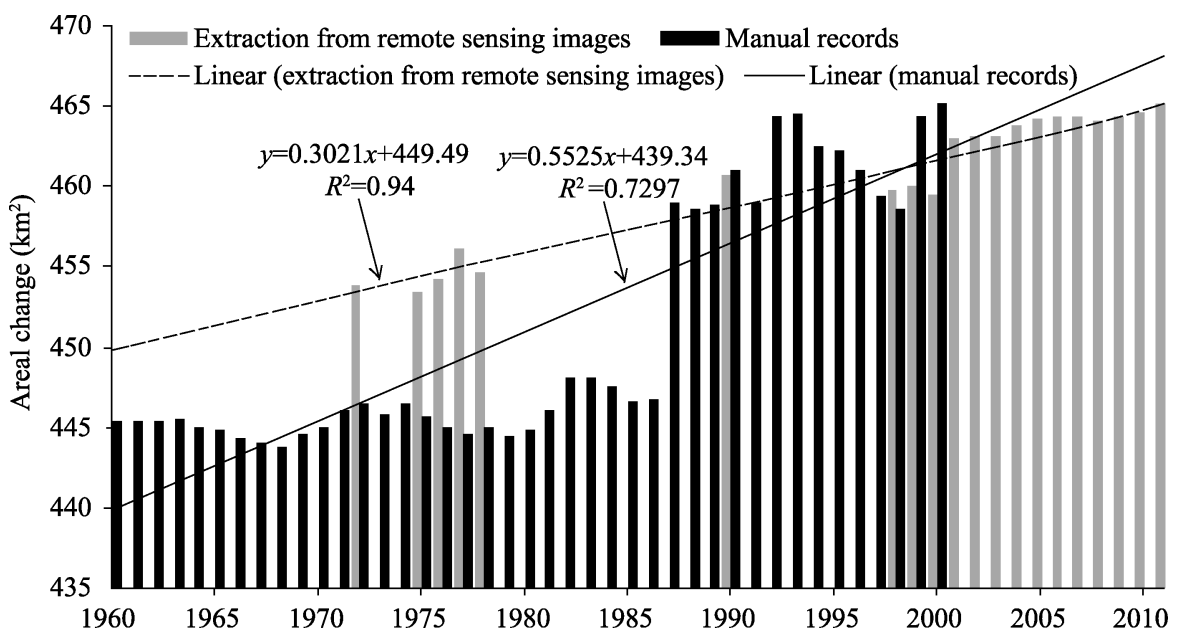

Fig. 11 Areal changes of Sayram Lake from different sources

obtained from 1960 to 2000 (Guo et al., 2003; Gao and Jia, 2005). Areal values are shown by the hatched rectangles in Fig. 11. The average value was $445 \mathrm{~km}^{2}$ from 1960 to 1985 , and from 1986 to 2000 it increased by $16 \mathrm{~km}^{2}$ to $461 \mathrm{~km}^{2}$.

To compare the difference and availability of areal values during the periods $1960-1985$ and from 1986-2000, we added the results extracted from remote sensing images (gray rectangles in Fig. 11). The difference between the two sets of values is negligible from 1986 to 2000, but there is greater difference before 1986. We infer that this is because of the different statistical methods used for areal values before and after 1986.

The two datasets from different sources showed the same increasing trend. The data from the remote sensing image are more reliable than those of manual records. Thus, we chose the images to extract the water body data and obtain the actual areal change of Sayram Lake over the past 40 years.

\subsection{Areal fluctuation of different years from re- mote sensing images}

Through comparing the acquisition time of remote sensing images, data from summer seasons (June-September) without cloud cover were selected to ensure consistency and reliability. The data fluctuate over the years (Table 2, Fig. 3). There were especially low areal values in 1998, 1999, and 2000 compared with other years.

There are several reasons that can cause fluctuation in extraction results from remote sensing images. The first is the seasonal difference; we selected an image with roughly the same acquisition date, but separated by more than three months. The second is regional differences of temperature and precipitation. Sayram Lake is in a region where melting glaciers and snow are the main water sources, and are subject to the current-year temperature and previous-year precipitation (especially the previous-winter snowfall). The third is 
a difference of extraction method. Deeper or shallower water can affect area data. The lacustrine and alluvial-lacustrine fan plains, especially the lake beach with growing vegetation (e.g. reeds) in the gentle topography west of the lake (Fig. 2), can affect the seasonal and annual area data values. Therefore, areal variation with season and year is complicated.

\subsection{Lake water amount estimation during climate change}

According to the principle of mass conservation, if the water supply into the lake (in-amount) is continuously greater than water consumed (out-amount), the lake water level rises, and lake area increases. This process is depicted in Fig. 12, in which the left portion represents water supply in the entire watershed, and the right shows water consumed in the lake region only. Upward arrows indicate rising values.

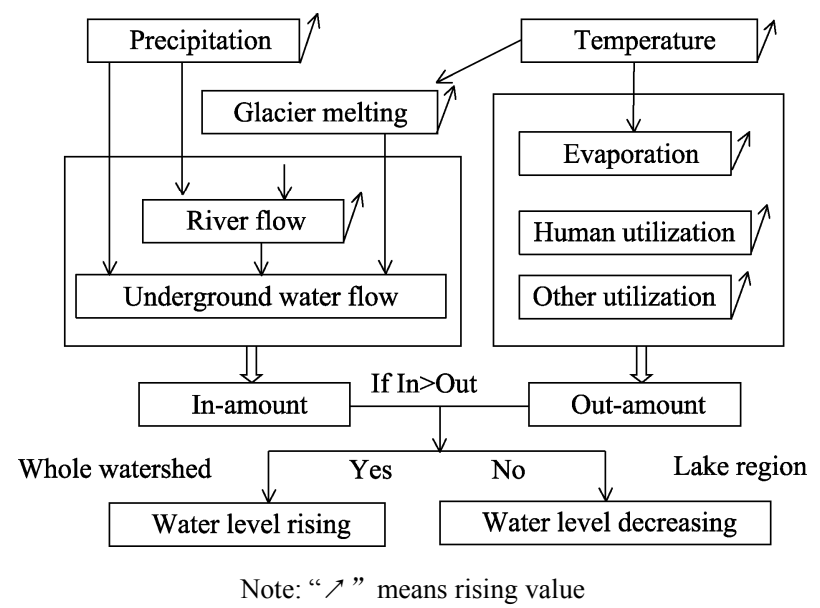

Fig. 12 Model of lake variation during climate change

When the temperature rises, melt water from glaciers and snow increases. With the continuous gentle increase in precipitation, water supply from river flow, underground water flow, and others increase. Moreover, with rising temperature, evaporation from the lake water surface intensifies. However, its area is smaller than that of the entire watershed, and the increase in evaporated water is less because of the high altitude. Finally, there is a very small effect from human activities. Consequently, when the in-amount exceeds the out-amount, the water level rises and the lake area expands.

According to the model (Fig. 12), we estimated the water volume from precipitation increase and water evaporation from warming temperature

The estimation of water volume from precipitation increase was based on Eq. 1. Because of the vertical zone distribution characteristics of the Tianshan Mountains, precipitation increases with elevation (Tang and Qu, 1992). Taking the elevation of Yining station $(1,000 \mathrm{~m}$ asl) as a benchmark, its elevation difference with Sayram Lake $(2,071.9 \mathrm{~m}$ asl) is about $1,000 \mathrm{~m}$, giving an elevation gradient $(E G)$ of 10. From the surface volume tool in ArcGIS, the surface area SA (3D) of the entire watershed above the lake water level was $1,365.57 \mathrm{~km}^{2}$. The average increase in the amount of precipitation $(A P)$ of the four meteorological stations was $82.89 \mathrm{~mm}$ over the past 40 years (Fig. 7). Therefore, the increase in water volume from increased precipitation $(I P)$ based on Eq. 1 was $11.32 \times 10^{8} \mathrm{~m}^{3}$.

The estimation of evaporation from rising temperature was based on Eq. 2. We reused the elevation gradient of 10 . When the elevation increases by $100 \mathrm{~m}$, evaporation decreases by $30 \mathrm{~mm}$ (Xaymurat, 2010). Taking the average evaporation intensity at Yining station (about 1,600 mm; Tang and Qu, 1992) as a benchmark, the evaporation difference of elevation gradient between the study area and the benchmark is $300 \mathrm{~mm}$; thus, the evaporation intensity $(E I)$ of the study area is $1,300 \mathrm{~mm}$. The ArcGIS surface volume tool gives a lake water area $(L A ; 2 \mathrm{D})$ of $453.2 \mathrm{~km}^{2}$. With a temperature rise of $1^{\circ} \mathrm{C}$, evaporation intensity increases by $5 \%$ (Tang and Qu, 1992), so the evaporation gradient $(E G)$ is 0.05 . Average increase in temperature $(A T)$ at the four meteorological stations was $1.82^{\circ} \mathrm{C}$ over the past 40 years. So, the volume of water evaporated from rising temperature $(R E)$ based on Eq. 2 is $0.30 \times 10^{8} \mathrm{~m}^{3}$.

According to a GIS-based calculations for hypsometry of the basin area of Sayram Lake, the water volume increased by $12.9 \times 10^{8} \mathrm{~m}^{3}$ over the past 40 years. Taking the increase in water volume from increased precipitation in the entire watershed as $11.32 \times 10^{8} \mathrm{~m}^{3}$, and the amount of water evaporated as $0.30 \times 10^{8} \mathrm{~m}^{3}$, the difference between in-amount and out-amount, $1.88 \times 10^{8} \mathrm{~m}^{3}$, represents the water volume from meltwater of the glaciers across the western high mountains over the past 40 years. Water consumption from human and animal drinking and evaporation in high 
mountains can be ignored.

From our rough calculation of the water balance in the entire watershed, we can conclude that the main cause of water volume increase in Sayram Lake is precipitation increase. Glacial meltwater has a small contribution, and the contribution of evaporation from rising temperature is smaller than that of precipitation increase. Thus, the in-amount exceeds the out-amount, which caused the continuous water volume increase over the past 40 years. In the future, the contribution from glacial meltwater may increase.

\section{Conclusions}

The change of Sayram Lake reflects the variation of the local climate. This study addressed the effects of climatic fluctuations on the changes of Sayram Lake over the past 40 years. We concluded that: 1) The areal values of the lake increased over the past 40 years by about $12 \mathrm{~km}^{2}$; 2) Both temperature and precipitation increased by $1.8^{\circ} \mathrm{C}$ and $82 \mathrm{~mm}$, respectively. The areal values show a linear relationship with local temperature and precipitation; 3) From the GIS-based calculation for hypsometry of the basin area of Sayram Lake, the lake water-level increased by $2.8 \mathrm{~m}$ and the water volume increased by $12.9 \times 10^{8} \mathrm{~m}^{3}$ over the past 40 years. The water balance of the entire watershed indicated that the main cause of increased water volume in the lake is from increased precipitation. Glacial meltwater contributes a small amount, and evaporation from rising temperature is negligible.

This research presented a method for estimating evaporation from rising temperature and lake expansion from increased precipitation. Based on this method, we determined the coupling effects of temperature and precipitation on changes in lake area and volume. Furthermore, the contributions of temperature and precipitation changes to lake water levels were identified.

A detailed analysis of the effects of climate fluctuations on lake water levels was also conducted. Area variation of Sayram Lake has negligible interference from human activities, and all variations resulted from natural processes. The findings of continuously increasing water supply and lake area concur with the current global climate processes. In the future, re- search into the response mechanism of areal variation of Sayram Lake to climate change must be intensified, and we foresee this to be a long-term project.

\section{Acknowledgments}

This work was financially supported by the National Science Technology Support Plan Project (2012BAH28B01-03) the National Natural Science Foundation of China (41171332), the National Science Technology Basic Special Project (2011FY110400-2), and the China Postdoctoral Science Foundation (2012M510526). We thank the Chinese National Weather Service for providing the long-term meteorological data. We also thank the editors and anonymous reviewers.

\section{References}

Angel J R, Kunkel K E. 2010. The response of Great Lakes water levels to future climate scenarios with an emphasis on Lake Michigan-Huron. Journal of Great Lakes Research, 36: 51-58.

Bai J, Cheng X, Li J L, et al. 2011. Changes of inland lake area in arid Central Asia during 1975-2007: a remote-sensing analysis. Journal of Lake Sciences, 23(1): 80-88.

Bates B C, Kundzewicz Z W, Wu S, et al. 2008. Climate change and water. Technical Paper of the Intergovernmental Panel on Climate Change, IPCC Secretariat, Geneva, 210.

CGIAR-CSI. 2008. SRTM 90 m Digital Elevation Data. International Centre for Tropical Agriculture (CIAT). [2008-08-19]. http://srtm. csi.cgiar.org.

Ding Y J, Liu S Y, Ye B S, et al. 2006. Climatic implications on variations of lakes in the cold and arid regions of China during the recent 50 years. Journal of Glaciology and Geocryology, 28(5): 623-632.

Du Y Y, Zhou C H. 1998. Automatically extracting remote sensing information for water bodies. Journal of Remote Sensing, 2(4): 264-269.

Earth Resources Observation and Science Center (EROS). 2013. USGS Global Visualization Viewer. Virginia: U.S. Geological Survey. [2013-01-15]. http://glovis.usgs.gov.

Fan Z L, Li J. 1984. Recent changes in the lakes of Xinjiang. Geographical Research, 3(1): 77-86.

Gao H Z, Jia Y L. 2005. The evolution characteristics of typical inland lakes in northwest china during the past 40 years and their mechanism. Journal of Arid Land Resources and Environment, 19(5): 93-96.

Guo N, Zhang J, Liang Y. 2003. Climate change indicated by the recent change of inland lakes in northwest China. Journal of Glaciology and Geocryology, 25(2): 211-214.

$\mathrm{Hu}$ R J, Ma H, Fan Z L, et al. 2002. The climate trend demonstrated by changes of the lakes in Xinjiang since recent years. Journal of Arid Land Resources and Environment, 16(1): 20-27. 
Li J L, Fang H, Bao A M, et al. 2011. Spatio-temporal analysis of recent changes of lake area and lake water level at high mountains in Central Asia. Resources Science, 33(10): 1839-1846.

Liu H, Jezekk C. 2004. Automated extraction of coastline from satellite imagery by integrating canny edge detection and locally adaptive thresholding methods. International Journal of Remote Sensing, 25(5): 937-958.

Luo J C, Sheng Y W, Shen Z F, et al. 2009. Automatic and high-precise extraction for water information from multispectral images with the step-by-step iterative transformation mechanism. Journal of Remote Sensing, 13(4): 604-615.

Ma D D, Zhang L P, Wang Q J, et al. 2003. Influence of the warm-wet climate on Sailimu Lake. Journal of Glaciology and Geocryology, 25(2): 219-223.

McFeeters S K. 1996. The use of normalized difference water index (NDWI) in the delineation of open water features. International Journal of Remote Sensing, 17(7): 1425-1432.

Ouma Y O, Tateishi R. 2006. A water index for rapid mapping of shoreline changes of five East African Rift Valley lakes: an empirical analysis using landsat TM and ETM+ data. International Journal of Remote Sensing, 27(15): 3153-3181.

Qin B Q. 1993. The response of interior lakes to climate change in Central Asia. Journal of Lake Sciences, 5(2):118-127.

Shi Y F, Zhang X S. 1995. The effect of climate change on surface water resources and future trend in the northwest arid region, China. Science in China: Series B, 25(9): 968-977.

Tang Q C, Qu Y G. 1992. Hydrology and Water Resources Utilization in Arid China. Beijing: Science Press.

Tao F L, Yokozawa M, Hayashi Y, et al. 2005. A perspective on water resources in China: interactions between climate change and soil degradation. Climatic Change, 68(1-2): 169-197.

Wang R, Ernst G, Gao Q Z. 2003. The recent change of water level in the Bosten Lake and analysis of its causes. Journal of Glaciology and Geocryology, 25(1): 60-64.

Xaymurat A. 2010. Analysis of characteristics and long-term trend of water surface evaporation of west Tianshan Area in last 50 years. Hydrology, 30(6): 88-92.

Xinjiang Institute of Geography, the Chinese Academy of Sciences. 1986. Tianshan Mountains Evolution. Beijing: Science Press.

Xinjiang Integrated Scientific Investigation Team of the Chinese Academy of Sciences. 1966. Xinjiang Hydrogeography. Beijing: Science Press.

Yang F X. 2011. Xinjiang Geomorphology and Environmental Effect. Beijing: Geology Press.

Yang H B, Wang Z M, Zhao H L, et al. 2011. Water body extraction methods study based on RS and GIS. Procedia Environmental Sciences, 10: 2619-2624.

Zhou C H, Luo J C, Yang C J, et al. 2000. Flood monitoring using multi-temporal AVHRR and Radarsat imagery. Photogrammetric Engineering \& Remote Sensing, 66(5): 633-638.

Zhou C H, Luo J C, Yang X M, et al. 2003. Geo-understanding and Analysis in Remote Sensing Image. Beijing: Science Press.

Zhu D G, Meng X G, Zheng D X, et al. 2007. Change of rivers and lakes on the Qinghai-Tibet Plateau in the past 25 years and their influence factors. Geological Bulletin of China, 26(1): 22-30. 